\title{
Respiratory Responses to Occlusion or Hypercapnic Blood Injection of the Anterior Inferior Cerebellar Artery in Cats
}

\author{
Shun-ichi KuWANA and Teijiro NatsuI \\ Department of Physiology, School of Medicine, Teikyo University, \\ Itabashi-ku, Tokyo, 173 Japan
}

\begin{abstract}
To examine whether the central chemoreceptors of respiration are located in the perfused area of the anterior inferior cerebellar artery (AICA), we occluded arteries or injected hypercapnic blood into arteries in the ventral surface of the medulla in anesthetized, paralyzed, and peripherally chemodenervated cats. Phrenic nerve activity, as an index of respiratory output, was augmented by an injection of hypercapnic blood into the vertebral artery. This vertebral-injection response decreased during bilateral occlusion of AICA. However, responses of phrenic nerve activity to the occlusion of AICA were complicated; activity increased in 19 cats, did not change in 10, and decreased in 9 during occlusion. In experiments with blood of various $P_{\mathrm{CO}_{2}}$ levels being bilaterally injected into AICA, phrenic discharges increased with increases of $P_{\mathrm{CO}_{2}}$. During the injection of constant $P_{\mathrm{CO}_{2}}$ blood into AICA, phrenic response to alveolar $P_{\mathrm{CO}_{2}}$ decreased by $80 \%$ compared with the original response. From these results, the blood flow and blood $P_{\mathrm{CO}_{2}}$ level of AICA seemed to be related to the central chemosensitivity for respiration. To examine the perfused area, the ventral surface $\mathrm{pH}$ of the medulla was measured with a micro-combination $\mathrm{pH}$ electrode ( $2 \mathrm{~mm}$ diameter). During the injection into AICA, pH in the rostral medulla depended on the $P_{\mathrm{CO}_{2}}$ of injected blood, and $\mathrm{pH}$ in other areas depended on the $P_{\mathrm{CO}_{2}}$ of systemic blood. Also, histological study of India ink injection into AICA showed that ink-filled vessels were exclusively observed in the rostral medulla. Thus, we conclude that at least part of the central chemoreceptors of respiration are located in the perfused area of AICA, that is, in the rostral medulla.
\end{abstract}

Key words : respiration, central chemoreceptor, medullary artery, occlusion, injection.

There is still uncertainty about the actual location of the central chemosensitive structure of respiration, as recent reviews have indicated (LOESCHCKE, 1982; Millhorn and Eldridge, 1986; BRuCE and Cherniack, 1987). Since the

Received for publication January 30, 1990 
observation of MITCHELL et al. (1963), a number of investigations have supported the proposition that the central respiratory chemoreceptors are located in discrete areas near the ventral surface of the medulla. Most of these studies employed the methods of application of acid, electrical stimulation, or cooling of the ventral surface of the medulla (SCHLÄFKE et al., 1970; LOESCHCKE et al., 1970). CRAGG et al. (1977) and KILEY et al. (1985) measured the $\mathrm{pH}$ of the medulla with a small $\mathrm{H}^{+}$ sensitive electrode and suggested that brain stem sites other than the ventral surface of the medulla might be chemosensitive.

On the other hand, it is generally agreed that the stimulus to chemoreceptors and the consequent respiratory response are closely linked to changes in the $\mathrm{pH}$ of extracellular fluid (ECF), which in turn changes rapidly with blood-born acid-base or $P_{\mathrm{CO}_{2}}$ alterations. Therefore, if the ECF pH could be locally changed, the site of chemosensitive structures may be identified.

In the previous study (Kuwana and NATSUI, 1988), in which we occluded arteries in the ventral surface of the medulla in anesthetized cats, we examined the occlusion effect on respiratory response to hypercapnic blood injection into the vertebral artery. The results showed qualitatively that among arteries the blood flow of the anterior inferior cerebellar artery (AICA) was related to this vertebral injection response. Furthermore, we have recently found that the regional ECF pH shifted to acid by the occlusion of the principal artery supplying tested regions and that the ECF $\mathrm{pH}$ response to vertebral injection of $\mathrm{CO}_{2}$-saturated saline was diminished during occlusion (ICHIKAWA et al., 1989). If the central chemoreceptors are perfused by AICA, its occlusion should induce an increase in respiratory output and a decrease in respiratory response to the vertebral injection of hypercapnic blood, and respiratory activity could be expected to be dependent on the $P_{\mathrm{CO}_{2}}$ level of injected blood into AICA.

To examine this hypothesis, we occluded AICA and injected blood with various levels of $P_{\mathrm{CO}_{2}}$ into AICA in anesthetized, paralyzed, and peripherally chemodenervated cats. The results suggested that the central chemosensitive structures of the respiratory control system are partly located in the perfused area of AICA. In addition, the perfused area of AICA was examined by regional $\mathrm{pH}$ measurement and histological study. Some of the results reported here have been presented in a preliminary report (KUWANA and NATSUI, 1987b).

\section{METHODS}

General. Fifty-five cats were intravenously anesthetized with chloraloseurethane (40 and $200 \mathrm{mg} / \mathrm{kg}$ ) after intramuscular premedication with ketamine $(25 \mathrm{mg} / \mathrm{kg})$. Since the combination of chloralose and urethane was previously demonstrated to maintain a stable depth of anesthesia for over $10 \mathrm{~h}$ (KUWANA and NATSUI, 1981), no additional anesthetics were used throughout the experiment.

Each cat was placed in a supine position on a table with a rigid head mounting. Body temperature was monitored with a rectal thermistor and controlled at $37-38^{\circ} \mathrm{C}$ 
with an electric heating pad. The trachea was cannulated in the mid-cervical region for artificial respiration and also for continuous monitoring of end-tidal $P_{\mathrm{CO}_{2}}$ and $P_{\mathrm{O}_{2}}$ by $\mathrm{CO}_{2}-\mathrm{O}_{2}$ analyzer (1H21, NEC San-ei Co., Tokyo). The femoral arteries on both sides and the right femoral vein were prepared for catheterization. Arterial blood pressure was measured from the catheter in the right femoral artery. After preparatory nerve surgery, the vagosympathetic trunks were cut bilaterally at the mid-cervical region and the carotid sinus nerves on both sides were cut at the level of their emergence from the glossopharygeal nerves.

In several cats, electrical stimulation of the sinus nerve was performed at the central cut-end with a bipolar hook electrode $(40 \mathrm{~Hz}$, duration of $1 \mathrm{~ms}$, intensity of $1-5 \mathrm{~V})$. The right phrenic nerve was exposed at the neck, sectioned at the low cervical region, and its central cut-end was placed on a pair of platinum electrodes in a pool of liquid paraffin. Paralysis was induced with pancronium bromide (Mioblock, $0.2 \mathrm{mg} / \mathrm{kg}$ ) injected into the right femoral vein, and artificial ventilation with room air was started. Thereafter, the same dose of pancronium bromide was administered hourly. The end-tidal $P_{\mathrm{CO}_{2}}$ was kept constant at $30-40 \mathrm{mmHg}$ by adjusting the ventilation.

We followed the surgical procedures described by LoESCHCKE et al. (1970) for exposing the ventral medulla. The rostral parts of the trachea and esophagus were pulled into the mouth and the muscles covering the occipital palate were removed. The occipital bone was opened ventrally with rongeur forceps between the tympanic bullae down to the foramen magnum, and the ventral part of the atlas and the dens axis were removed. In several cats, the medial wall of the tympanic bullae was chipped away and the bone was opened laterally to the petrous portion of the temporal. The dura mater covering the ventral medulla was cut in the mid-line by microcautery, retracted laterally, and tacked to the bone either by cauterizing or by epoxy glue.

Occlusion of the artery in the ventral surface of the medulla. The procedure used for occlusion of the medullary artery was previously described (KUWANA and NATSUI, 1988). The arteries in the ventral surface of the medulla were isolated from the pia-arachnoid. Occlusion was performed by means of ligation with fine silk sutures. For reversible occlusion, the artery was ligated together with a piece of fine polyethylene tube which had been put over the artery, enabling us to easily untie the knot by pulling out the tube. This occlusion procedure was less damaging for the vessel, but it could not be applied for vessels having a number of branches. In the present study, we occluded the anterior (AICA) and/or posterior inferior cerebellar arteries (PICA) in the portion as closely as possible to the ramifying point from the vertebral-basilar artery (Fig. 1).

Injection of blood into the artery. Hypercapnic blood was injected into a vertebral artery in 26 cats, and blood with various levels of $P_{\mathrm{CO}_{2}}$ was injected into AICA in 9 cats. For the vertebral artery injection, the right vertebral artery was exposed between the axis and atlas vertebra. A catheter (O. D., $0.8 \mathrm{~mm}$ ) was inserted into the vertebral artery with the tip in the cranial direction. Vertebral injection 


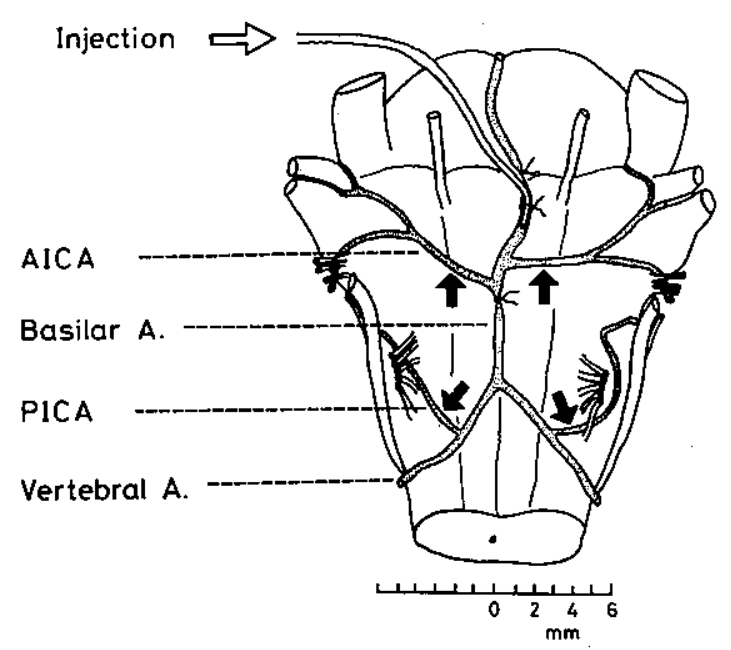

Fig. 1. Schematic representation of the ventral view of the medulla oblongata and principal arteries. AICA, anterior inferior cerebellar artery; PICA, posterior inferior cerebellar artery. Occluded vessel portions of AICA and PICA in the occlusion study are indicated by solid arrows. In the AICA-injection study, a catheter was inserted into the basilar artery at the border region between the pons and medulla with the tip in the caudal direction. For injection into AICA, the basilar artery in the caudal region of the ramifying point of AICA was ligated.

and occlusion of cerebellar arteries were repeatedly done in each cat. For the injection into AICA, a catheter (O.D., $0.3 \mathrm{~mm}$ ) was introduced at the border region between the pons and medulla into the basilar artery with the tip in the caudal direction (Fig. 1). During injection, the basilar artery in the caudal region of the ramifying point of AICA was ligated. This catheter was covered with a nylon tube through which warm water $\left(38^{\circ} \mathrm{C}\right)$ was being circulated.

About $10 \mathrm{ml}$ of blood, to be used for later injection, was drawn from the animal's own femoral artery. After the addition of $1 \mathrm{ml}$ of heparin $(1,000$ units), it was mixed with a gas mixture of $80 \% \mathrm{CO}_{2}$ in $\mathrm{O}_{2}$ in a syringe. This syringe was immersed in a water bath of $38^{\circ} \mathrm{C}$. The blood $P_{\mathrm{CO}_{2}}$ was varied according to different mixing times. The mixing time was about $30 \mathrm{~min}$ for the vertebral injection and from 5 to $30 \mathrm{~min}$ for the injections into AICA. The $P_{\mathrm{CO}_{2}}$ and $\mathrm{pH}$ of the blood equilibrated with the gas mixture were measured with a blood gas analyzer (BMS-MK2, Radiometer, Copenhagen). However, most of the blood $P_{\mathrm{CO}_{2}}$ was estimated from the relationship between $P_{\mathrm{CO}_{2}}$ and $\left[\mathrm{H}^{+}\right]\left(P_{\mathrm{CO}_{2}}=0.92\left[\mathrm{H}^{+}\right]\right.$ -11.6 , correlation coefficient $=0.98$ ) which was obtained empirically both in vivo and in vitro (KuwanA and NATSUI, 1987a). The injection was carried out with a syringe infusion pump (575, Princeton Medical Instruments, Natick, MA, U.S.A.). The vertebral injection was given at a rate of $3 \mathrm{ml} / \mathrm{min}$ for a duration of $10 \mathrm{~s}$ (KuwanA and NaTsur, 1988). For this injection, the mean $P_{\mathrm{CO}_{2}} \pm$ S.D. and 
mean $\mathrm{pH} \pm$ S.D. of blood were $190.4 \pm 63.5 \mathrm{mmHg}$ and $6.679 \pm 0.140$, respectively. The injection into AICA was given at a rate of $0.4-1.0 \mathrm{ml} / \mathrm{min}$ for a duration of 2-5 min.

Measurement of medullary surface pH. In 5 cats, $\mathrm{pH}$ of the ventral surface of the medulla was measured to determine whether an area had been perfused by the injected blood into AICA or not. Surface $\mathrm{pH}$ was measured with a micro-combination $\mathrm{pH}$ probe ( $2 \mathrm{~mm}$ diameter, $\mathrm{MI}-410$, Microelectrodes Inc., $\mathrm{NH}$, U.S.A.) and a pH meter (F-7ss, Hitachi-Horiba, Kyoto, Japan). The output of the $\mathrm{pH}$ meter was amplified with a DC amplifier. Calibration of the $\mathrm{pH}$ electrode was done in vitro with standard phosphate buffers (S1500 and S1510, Radiometer). Thus all the in vivo $\mathrm{pH}$ measurements were reported as changes from the baseline. The electrode was mounted in a balanced holder which moved freely in a vertical direction, and was gently placed on the medullary surface that was free from the major artery.

Measurements of $\mathrm{pH}$ were performed in three sites of the originally described respiratory chemosensitive areas: the "rostral," "intermediate," and "caudal". areas (MITCHELl et al., 1963; SCHLÄFKe et al., 1969; LOESCHCKE et al., 1970). For the rostral area, the rostral edge of the $\mathrm{pH}$ electrode was placed at a level $1-2 \mathrm{~mm}$ caudal to the point of exit from the medullary surface of the 6th nerve root (see Fig. 9). For the intermediate area; the caudal edge of the electrode was placed at a level $1 \mathrm{~mm}$ rostral to the rostral rootlets of the 12 th nerve, and for the caudal area the center of the electrode was placed at a level of the middle of the 12th nerve rootlets. In all cases the center of the electrode was $3 \mathrm{~mm}$ lateral to the mid-line.

At the end of the experiment, the perfused area was determined by injecting India ink (No. 591017, Rotring, Hamburg, F.R.G.) into AICA. Just before the animal was sacrificed with an overdose of pentobarbital sodium, ink was injected into AICA at the same rate as that of blood injection. At the same time that arterial pressure fell dure to the anesthetic, the injection was stopped. The head was then removed and fixied in $20 \%$ formaldehyde solution. The brain was carefuly removed 2 days later. Cross sections $50 \mu \mathrm{m}$ thick between the sixth root and the first cervical root were cut on, a freezing microtome and cleared in xylene.

Data handling. Phrenic nerve discharges were used as an index of respiratory output. Amplified nerve discharges were simultaneously monitored on a cathode-ray oscilloscope and a sound monitor. The signal was also led to an integrator with a time constant of $47 \mathrm{~ms}$. The integrator output, end-tidal $P \mathrm{CO}_{2}$, arterial blood pressure, and medullary surface $\mathrm{pH}$ were recorded with a pen recorder (8S, NEC San-ei Co., Tokyo).

The inspiratory activity for each breath was determined from the peak amplitude of integrated phrenic activity which had been defined as tidal activity (ELDRIDGE et al., 1981). In the steady-state studies, the averaged value. of tidal phrenic activity for $1 \mathrm{~min}$ was used.

In the vertebral injection studies, minute phrenic activity was calculated as the algebraic sum of tidal activity for $1 \mathrm{~min}$. For evaluating the stimulating effect of 
the vertebral injection on respiration, the difference in minute phrenic activity $(\Delta \mathrm{min}$ phrenic activity) was used, which was determined as the minute value for $1 \mathrm{~min}$ from start of injection minus that for $1 \mathrm{~min}$ before injection (Fig. 3). In order to compare the findings among the different cats, $\Delta$ min phrenic activity during occlusion of the medullary artery was expressed as a percentage of that found in the control injection in an individual cat. $\Delta$ min phrenic activity was dependent on the injection rate, duration, and $P_{\mathrm{CO}_{2}}$ level of the injected blood, and was regarded as the index of the excitability of the central chemoreceptors (KUWANA and NATSUI, 1987a).

\section{RESULTS}

Effect of occlusion of medullary arteries on phrenic nerve activity

We studied the effect of occlusion of AICA and/or PICA on phrenic nerve activity in 43 cats. Figure 2 shows an example of phrenic response to the occlusion of AICA. The amplitude of integrated phrenic discharges increased by bilateral occlusions and reached the steady-state after about $1 \mathrm{~min}$ from the start of occlusion. Phrenic activity returned gradually to the control level with the opening of AICA. Unilateral occlusion did not produce changes in phrenic discharges. The augmentation of phrenic activity during the occlusion of AICA was observed in 19 out of 38 cats. In the remaining 19 cats, phrenic activity did not change or was even observed to decrease during occlusion. Individual differences in phrenic response to occlusion were observed not only during the occlusion of AICA but also of PICA.

The results of these experiments are summarized in Table 1, where end-tidal

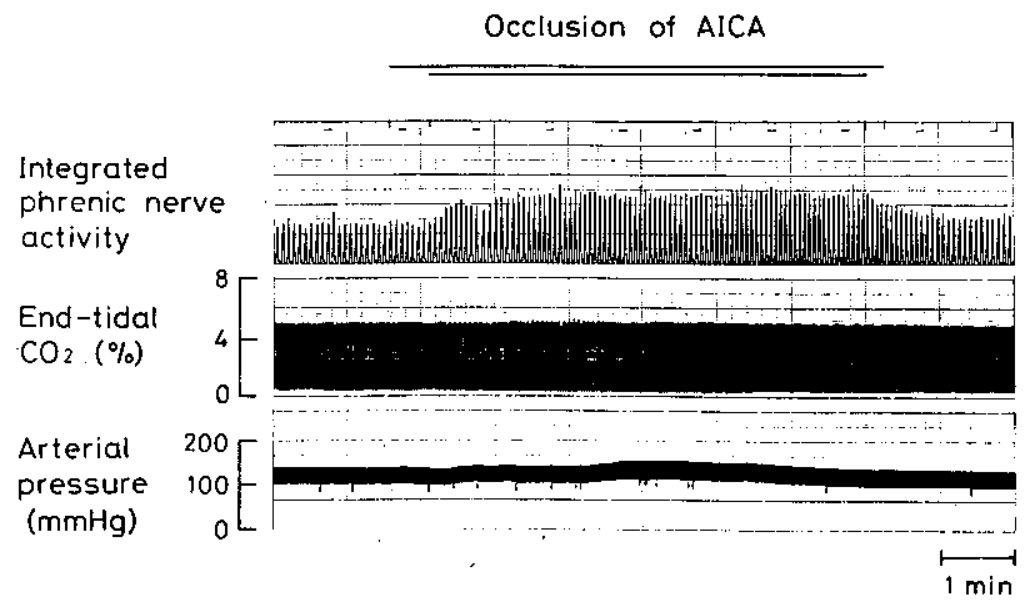

Fig. 2. Effect of occlusion of AICA on phrenic nerve activity at constant end-tidal $P_{\mathrm{CO}_{2}}$. Occlusion periods of AICAs are indicated by the respective horizontal bars above the panel. 
Table 1. Effect of occlusion of medullary arteries on phrenic nerve activity at end-tidal $P_{\mathrm{CO}_{2}}$ of $30-40 \mathrm{mmHg}$.

\begin{tabular}{lcccc}
\hline Occlusion & $\begin{array}{l}\text { Number of } \\
\text { cats tested }\end{array}$ & Increase & No effect & Decrease \\
\hline AICA & 38 & 19 & 10 & 9 \\
PICA & 20 & 2 & 13 & 5 \\
AICA + PICA & 20 & 0 & 8 & 12 \\
\hline
\end{tabular}

A. Control

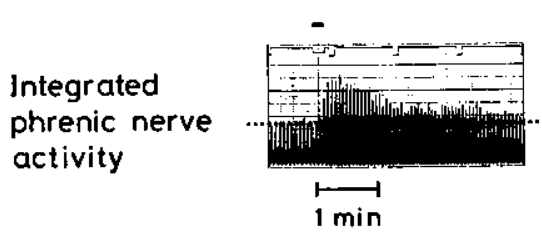

B. Occlusion of AICA

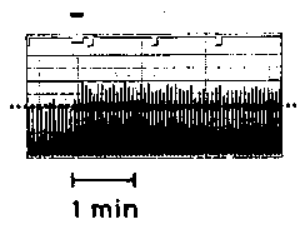

Fig. 3. Effect of hypercapnic blood injection into the vertebral artery on phrenic nerve activity before (A) and during occlusion of AICA (B). The blood with $P_{\mathrm{CO}_{2}}$ $130 \mathrm{mmHg}$ was injected at a rate of $3 \mathrm{ml} / \mathrm{min}$ and a duration of $10 \mathrm{~s}$ under constant end-tidal $P_{\mathrm{CO}_{2}}$, indicated by horizontal bar above the panel. Dotted line indicates baseline of tidal phrenic activity.

$P_{\mathrm{CO}_{2}}$ was kept constant between 30 and $40 \mathrm{mmHg}$. During the occlusion of PICA, discharges increased in 2 cats, were unchanged in 13, and decreased in 5. Bilateral occlusions of both AICA and PICA did not affect the phrenic activity (8 cats) or elicited a decrease (12 cats). In extreme cases, phrenic discharges completely disappeared by bilateral occlusions of both AICA and PICA, and electrical stimulation of the carotid sinus nerve was ineffective during these occlusions.'This indicates that severe ischemia of the lateral medulla may be induced by the bilateral occlusions of AICA and PICA.

\section{Effect of occlusion of medullary arteries on vertebral-injection response}

Hypercapnic blood injection into the vertebral artery and occlusion of the medullary arteries were performed in 26 cats. Figure 3 shows an example of the phrenic response to the vertebral injection before and during occlusion of AICA. Blood with a $P_{\mathrm{CO}_{2}}$ level of $130 \mathrm{mmHg}$ was injected at a rate of $3 \mathrm{ml} / \mathrm{min}$ during a 10-s duration. Before occlusion, phrenic discharges increased after a delay of about $5 \mathrm{~s}$ after the start of the injection, and the maximal activity was seen within a few bursts, after which a gradual decrease was observed (Fig. 3A). Augmentation of phrenic activity by the injection was seen during the occlusion of AICA. However, the amplitude of the maximal phrenic activity was less than that before occlusion and the recovery process from phrenic augmentation was found to be rather 


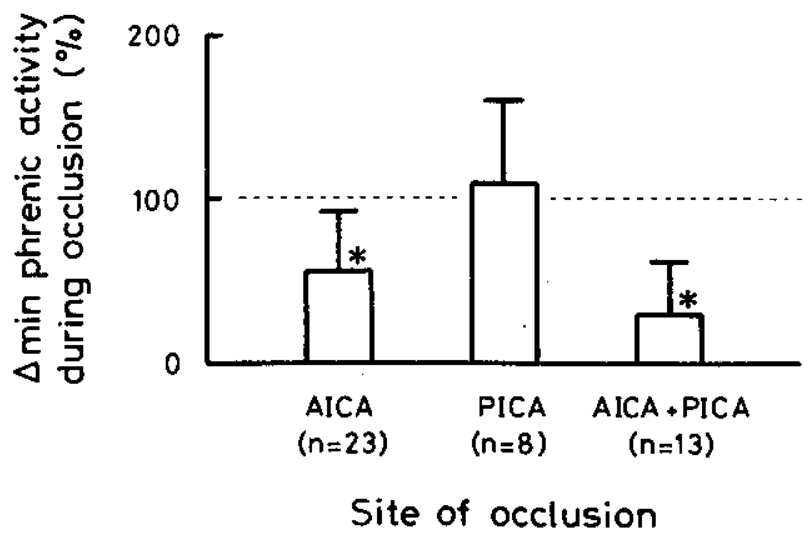

Fig. 4. Effect of occlusion of medullary arteries on induced phrenic response by vertebral injection. $\Delta$ min phrenic activity during occlusion was normalized by assigning a value of $100 \%$ to that found in control injection in an individual cat. Vertical bar represents \pm S.D. of the mean. ${ }^{*} p<0.01$, as compared to control, Student's $t$-test. $n$, number of cats tested.

prolonged (Fig. 3B). In this example, occlusion of AICA caused a decrease in the phrenic response to the vertebral injection. Such injections and occlusions were performed repeatedly at end-tidal $P_{\mathrm{CO}_{2}}$ levels of between 30 and $50 \mathrm{mmHg}$ in each cat.

For evaluating the occlusion effect on the phrenic response to the vertebral injections, $\Delta \mathrm{min}$ phrenic activity during occlusion was expressed as a percentage of that before occlusion. The results are summarized in Fig. 4. During the occlusion of AICA, the mean \pm S.D. of $\Delta$ min phrenic activity was $55.3 \pm 36.9 \%$, meaning that this occlusion caused the phrenic response to the injection to decrease. During the occlusion of PICA, the mean \pm S.D. of $\Delta$ min phrenic activity was $109.0 \pm 51.5 \%$, indicating that there was no effect. $\Delta$ min phrenic activity during occlusion of both AICA and PICA decreased in all cats examined, with the mean \pm S.D. being $30.5 \pm 32.9 \%$. In cases where the spontanous phrenic discharges disappeared by the occlusions of AICA and PICA, the injections did not induce the discharges to reappear.

\section{Effect of injection into AICA on phrenic activity}

Figure 5 shows an example of injection of blood with two levels of $P_{\mathrm{CO}_{2}}$ into AICA. Injection was performed at a rate of $0.4 \mathrm{ml} / \mathrm{min}$ at constant end-tidal $P_{\mathrm{CO}_{2}}$. When the $P_{\mathrm{CO}_{2}}$ of the injected blood was $38.4 \mathrm{mmHg}$, phrenic discharges diminished and completely disappeared within $1 \mathrm{~min}$ from the start of the injection. However, the injection of blood with $P_{\mathrm{CO}_{2}} 102 \mathrm{mmHg}$ induced the augmentation of the phrenic discharges. In the steady-state condition $1 \mathrm{~min}$ after the start of the injection, the phrenic activity seemed to depend on the $P_{\mathrm{CO}_{2}}$ level of injected blood.

We then examined the effect of the injection of blood with various $P_{\mathrm{CO}_{2}}$ levels 


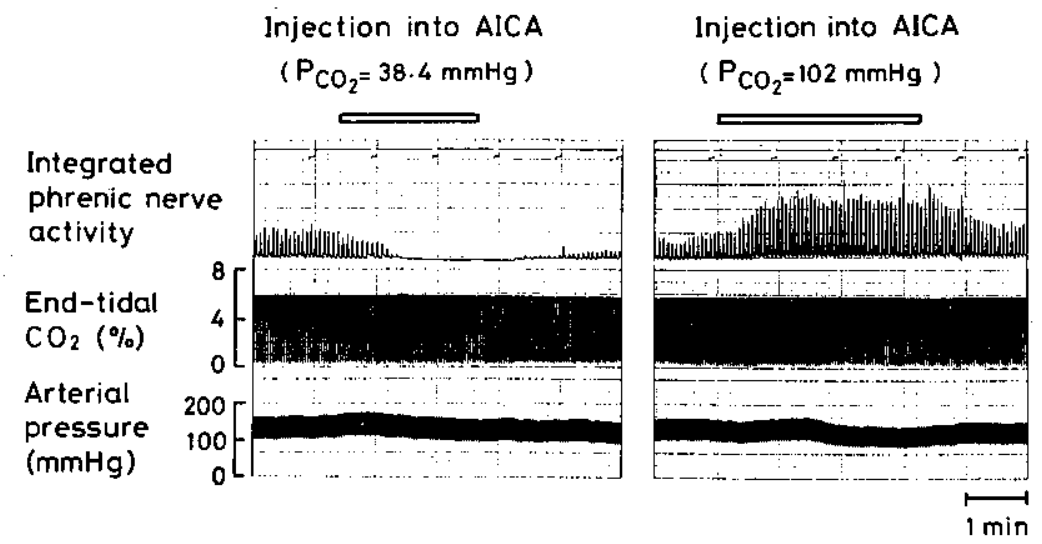

Fig. 5. Responses of phrenic nerve activity to injection of blood with low $P_{\mathrm{CO}_{2}}$ $(38.4 \mathrm{mmHg})$ and high $P_{\mathrm{CO}_{2}}(102 \mathrm{mmHg})$ into AICA at constant end-tidal $P_{\mathrm{CO}_{2}}$. Injection was performed at a rate of $0.4 \mathrm{ml} / \mathrm{min}$ and injection periods are indicated by open bars above the panels.

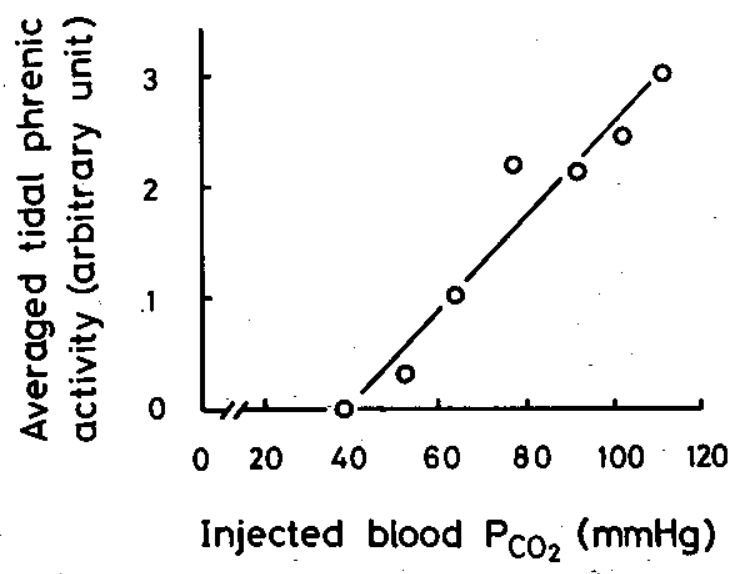

Fig. 6. Relationship between blood $P_{\mathrm{CO}_{2}}$ injected into AICA and phrenic nerve activity. Average tidal phrenic activity was calculated for $1 \mathrm{~min}$ up to the end of injection. Data were obtained from the same cat as Fig. 5.

on phrenic activity. Figure 6 shows the relationship between $P_{\mathrm{CO}_{2}}$ of injected blood and average tidal phrenic activity obtained for $1 \mathrm{~min}$ up to the end of the injection. Tidal activity was seen to increase linearly, with increases of $P_{\mathrm{CO}_{2}}$ of injected blood. However, this phrenic response to injected blood $P_{\mathrm{CO}_{2}}$ shifted toward higher $P_{\mathrm{CO}_{2}}$ in comparison to that of end-tidal $P_{\mathrm{CO}_{2}}$. A similar linear relationship between $P_{\mathrm{CO}_{2}}$ of injected blood and phrenic activity was also obtained in two other cats (data not shown).

In addition, we tried to determine whether phrenic activity was completely 


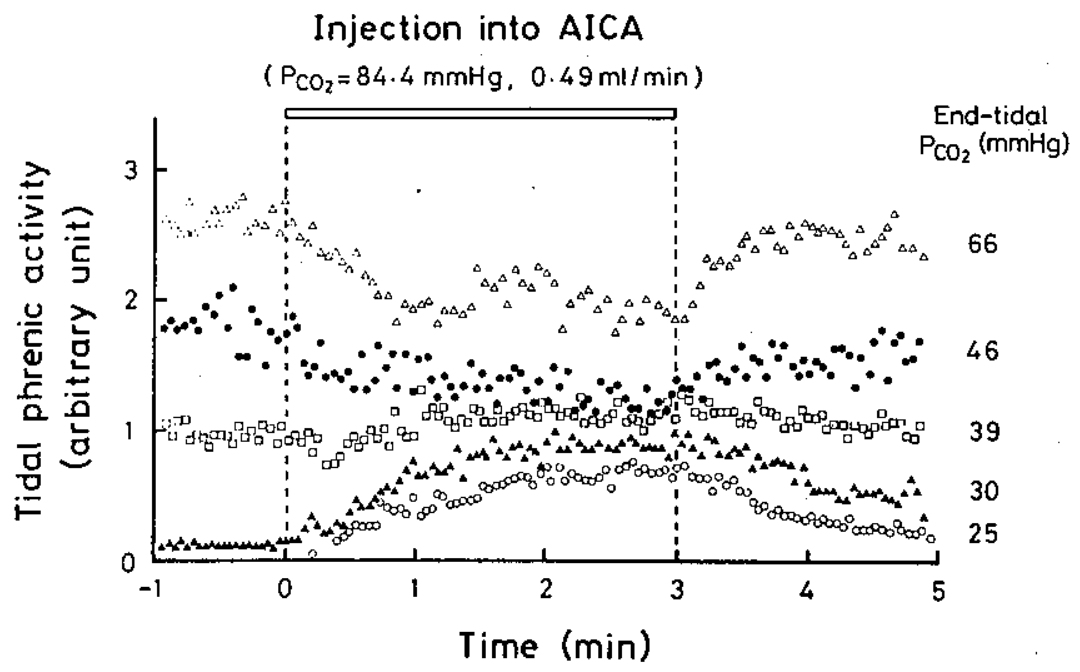

Fig. 7. Breath-by-breath response of phrenic nerve activity during injection of constant $P_{\mathrm{CO}_{2}}$ blood into AICA at various levels of end-tidal $P_{\mathrm{CO}_{2}}$. Injection period is indicated by open bar above the panel. Values of end-tidal $P_{\mathrm{CO}_{2}}$ are indicated on the right of the panel.

controlled by $P_{\mathrm{CO}_{2}}$ of the injected blood into AICA or not. Blood with constant $P_{\mathrm{CO}_{2}}$ was injected at various levels of end-tidal $P_{\mathrm{CO}_{2}}$. Figure 7 shows the tidal phrenic activity changes during the injection of blood with a $P_{\mathrm{CO}_{2}}$ level of $84.4 \mathrm{mmHg}$ (injection rate of $0.49 \mathrm{ml} / \mathrm{min}$, duration of $3 \mathrm{~min}$ ) at various levels of end-tidal $P_{\mathrm{CO}_{2}}$. At an end-tidal $P_{\mathrm{CO}_{2}}$ lower than $39 \mathrm{mmHg}$, the injection produced an increase in tidal phrenic activity, but at a level higher than $39 \mathrm{mmHg}$ the phrenic activity became less. The amplitudes of tidal phrenic activity during the injection seem to converge at that $39 \mathrm{mmHg}$ level.

Figure 8 shows the relationship between tidal phrenic activity and end-tidal $P_{\mathrm{CO}_{2}}$ before (open circle) and during injection (closed circle) obtained from the same experimental run as that of Fig. 7. The phrenic response to end-tidal $P_{\mathrm{CO}_{2}}$ decreased markedly during the injection. If the slope of the response curve at the linear portion (end-tidal $P_{\mathrm{CO}_{2}}$ between 30 and $50 \mathrm{mmHg}$ ) before the injection was assigned a value of $100 \%$, the slope during the injection declined to $19.1 \%$. This phrenic response to the end-tidal $P_{\mathrm{CO}_{2}}$ was obtained from 6 cats, in which blood with $P_{\mathrm{CO}_{2}}$ of $69.2 \pm 23.3 \mathrm{mmHg}$ (mean \pm S.D.) was injected into AICA. The mean slope \pm S.D. of the phrenic response curve during the injection obtained from the 6 cats was $22.7 \pm 20.2 \%$. This indicates that phrenic activity during the injection was affected not only by the $P_{\mathrm{CO}_{2}}$ level of AICA but also by the level of end-tidal $P_{\mathrm{CO}_{2}}$.

\section{Perfused area by injected blood into AICA}

Figure 9 shows the $\mathrm{pH}$ responses in the ventral surface of the medulla to 


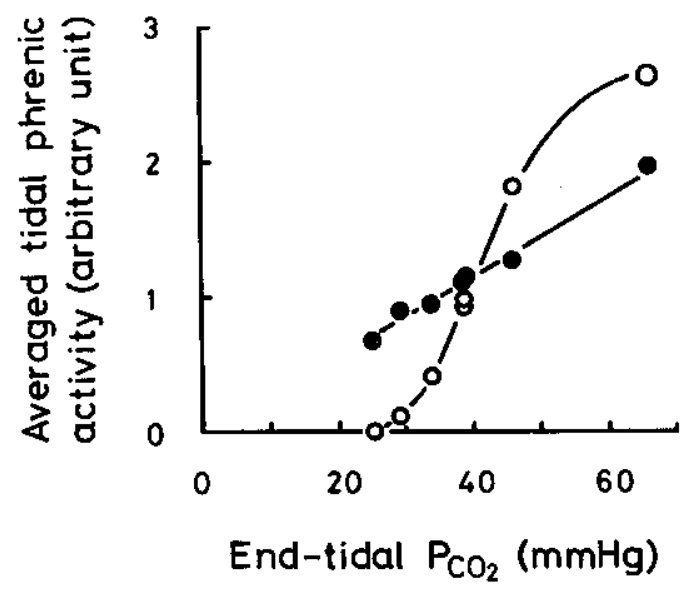

Fig. 8. Relationship between end-tidal $P_{\mathrm{CO}_{2}}$ and phrenic nerve activity before and during injection of constant $P_{\mathrm{CO}_{2}}(84.4 \mathrm{mmHg})$ blood into AICA. Average tidal phrenic nerve activities were calculated for $1 \mathrm{~min}$ up to the start $(O)$ and for $1 \mathrm{~min}$ up to the end (๑) of injection. Data were obtained from the same cat as Fig. 7.

inhalation of a hypercapnic gas mixture $\left(8 \% \mathrm{CO}_{2}\right.$ in $\left.\mathrm{O}_{2}\right)$ before and during the injection of blood into AICA. Before the injection, the surface $\mathrm{pH}$ of the three tested areas began to become acidic about $10 \mathrm{~s}$ after the onset of the inhalation of the mixture, and continued to shift to acid progressively as inhalation continued. The $\mathrm{pH}$ was the most acid about $10 \mathrm{~s}$ after the cessation of the inhalation and then returned to the control level as end-tidal $P_{\mathrm{CO}_{2}}$ decreased. This acidic shift indicates that hypercapnic blood reached these areas from the lung.

By the injection of blood with $P_{\mathrm{CO}_{2}} 78.3 \mathrm{mmHg}$, the rostral $\mathrm{pH}$ shifted to acid but the $\mathrm{pH}$ values of the caudal and intermediate areas did not change. Then, during the injection, the rostral $\mathrm{pH}$ response to the inhalation of the hypercapnic gas mixture decreased markedly, but the caudal and intermediate area responses were similar to those before the injection. These results indicate that the rostral area was perfused by the injected blood and the other areas were perfused by systemic arterial blood.

The perfused area was also determined by histological study. Figure 10 shows the cross sections of the medulla after the injection of India ink into AICA. The ink-perfused area is indicated by the dotted area. In the section through the rostral chemosensitive area (section, +6.0 ), ink-filled vessels were observed throughout. In the more caudal portion of this region the stained area was dorsally confined (section, +3.0 ), and more rostrally it was seen in the lateral portion (section, +9.5 ). In the section through the caudal chemosensitive area (section, +0.5 ), ink-containing vessels were completely absent. These results clearly indicate that the injected solution into AICA exclusively perfused the rostral medulla. 


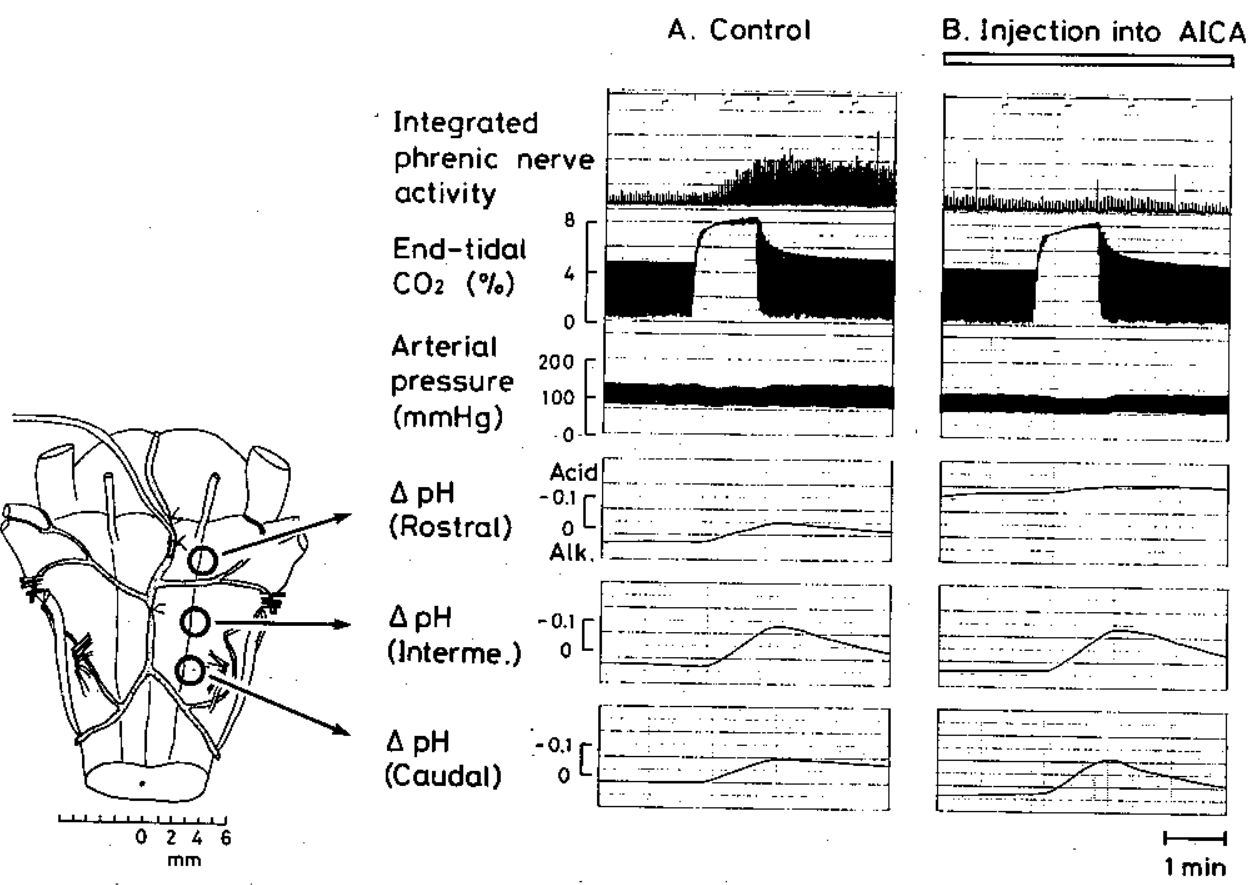

Fig. 9. Medullary suface $\mathrm{pH}$ response to inhalation of hypercapnic gas mixture before (A) and during injection of hypercapnic blood into AICA (B). In this example, blood with $P_{\mathrm{CO}_{2}} 78.3 \mathrm{mmHg}$ was injected at the rate of $0.49 \mathrm{ml} / \mathrm{min}$. Hypercapnic gas mixture $\left(8 \% \mathrm{CO}_{2}\right.$ in $\left.\mathrm{O}_{2}\right)$ was inhaled for $1 \mathrm{~min}$. Measurement of $\mathrm{pH}$ was done in three areas, which were originally described as chemosensitive areas: rostral, intermediate, and caudal areas. These sites are indicated by circles in the sketched ventral medulla.

\section{Phrenic activity and rostral $\mathrm{pH}$}

Before the injection of blood, phrenic activity followed closely the $\mathrm{pH}$ changes of the ventral surface in the three tested areas (Fig. 9). During the injection, the phrenic response to the inhalation of the hypercapnic gas mixture seemed to be correlated with the $\mathrm{pH}$ response in the rostral area but not in the two other areas. Therefore, tidal phrenic activity versus rostral $\mathrm{pH}$ before and during the injection of blood with various levels of $P_{\mathrm{CO}_{2}}$ were plotted in Fig. 11. Phrenic activity during the injection increased with a decrease of $\mathrm{pH}$ in the rostral area as the $P_{\mathrm{CO}_{2}}$ level of injected blood increased (closed circles). However, the phrenic response to the injection was not correlated with the $\mathrm{pH}$ response. For example, when blood with $P_{\mathrm{CO}_{2}} 55.0 \mathrm{mmHg}$ was injected into AICA, rostral $\mathrm{pH}$ did not change and the phrenic activity decreased (indicated by arrow). These results demonstrate that the surface $\mathrm{pH}$ in the rostral area we measured does not provide a unique stimulus to phrenic nerve activity. 


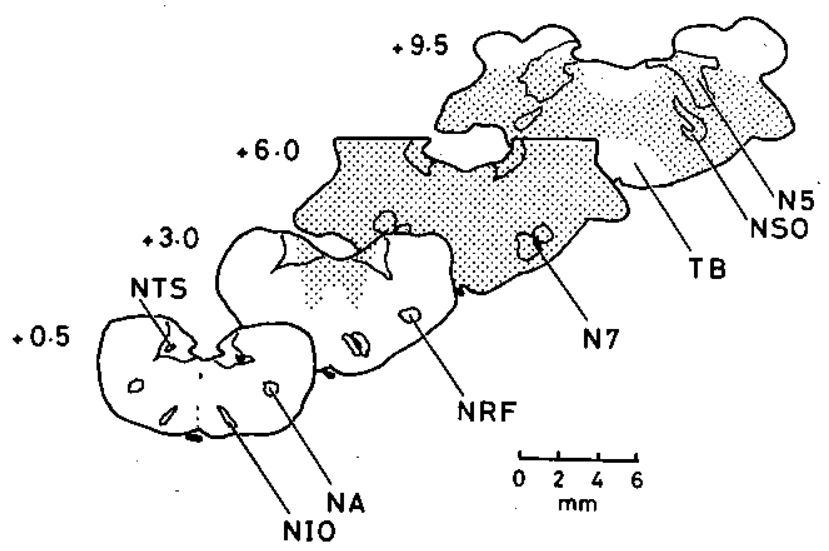

Fig. 10. Anatomical maps of the perfused area after India ink injection into AICA. The stained area, which contains the ink-filled vessels, is indicated by the dotted regions. Approximate levels of the sections in $\mathrm{mm}$ rostral $(+)$ to the obex are indicated to the left of each section. Some relevant structures are schematically represented: NTS, nucleus of solitary tract; NIO, inferior olivary nucleus; NA, nucleus ambiguus; NRF, retrofacial nucleus; N7, facial nucleus; TB, trapezoid body; NSO, superior olivary nucleus; N5, trigeminal motor nucleus.

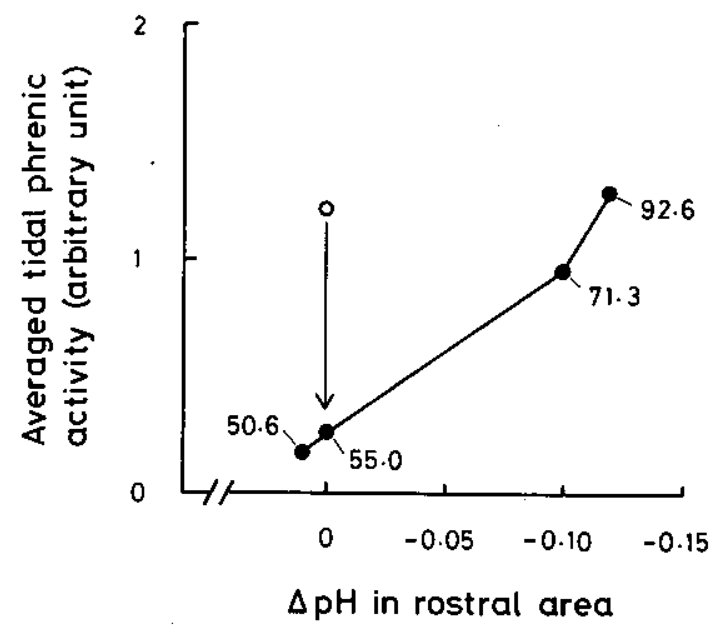

Fig. 11. Relations, in one cat, of phrenic activity and ventral surface $\mathrm{pH}$ in rostral medulla before (O) and during injection of blood with various levels of $P_{\mathrm{CO}_{2}}$ into AICA ( ). Numbers on plots represent $P_{\mathrm{CO}_{2}}$ values $(\mathrm{mmHg}$ ) of injected blood. End-tidal $P_{\mathrm{CO}_{2}}$ was kept constant at $38 \mathrm{mmHg}$, and each injection was done at a rate of $0.49 \mathrm{ml} / \mathrm{min}$ for a duration of $3 \mathrm{~min}$. Average phrenic activities were calculated for $1 \mathrm{~min}$ up to the start $(O)$ and for $1 \mathrm{~min}$ up to the end $(\bullet)$ of injection. When the blood with $P_{\mathrm{CO}_{2}} 55.0 \mathrm{mmHg}$ was injected, surface $\mathrm{pH}$ did not change but phrenic activity was decreased (indicated by arrow). 


\section{DISCUSSION}

The main findings in this experiment were 1) that the occlusion of AICA caused the phrenic response to a vertebral injection to decrease, 2) that phrenic activity was dependent on the $P_{\mathrm{CO}_{2}}$ level of the injected blood into AICA, indicating that phrenic activity is, at least under the present experimental conditions, driven by the input from central chemoreceptors, and 3) that injected blood into AICA perfused exclusively in the rostral medulla. These results strongly suggest that the central chemosensitive structures are located in the rostral medulla. However, neither the $P_{\mathrm{CO}_{2}}$ levels of AICA nor the surface $\mathrm{pH}$ in the rostral medulla represent a unique stimulus to phrenic discharges. Thus, we can conclude that the neural mechanisms approximately comprising the rostral half of the medulla are only partly involved in the respiratory chemoreception.

Effect of occlusion of the medullary arteries on respiration. The results of the present study show that the effect of occlusion of the medullary arteries on the phrenic nerve activity is complicated. In the previous study, we showed that the cerebral vascular system anastomosed between pial vessels and that the patterns of anastomoses differed from one another (KUWANA and NATSUI, 1988). The findings suggested that the blood flow to an area could not be stopped easily by the occlusion of one vessel because of the retrograde blood flow through the anastomotic area. Furthermore, CHAPMAN et al. (1979) studied the effects of the reduction of brain blood flow on ventilation and reported a complex ventilatory response that was related to the severity of brain ischemia; moderate reduction stimulated and severe reduction depressed the ventilation. Therefore, the increase of phrenic activity during the occlusion of AICA or PICA may be due to a moderate reduction of the blood flow, whereas the decrease of phrenic activity may be a result of a marked flow reduction in the central chemoreceptors or respiratory center.

If a particular artery supplies the blood to an area containing the central chemoreceptors, a moderate decrease of blood flow by occlusion would cause an increase in spontaneous phrenic activity because of the accumulation of $\mathrm{CO}_{2}$, and a decrease in phrenic response to the vertebral injection because of impaired circulation. Recently, we measured the regional $\mathrm{pH}$ of extracellular fluid (ECF) with a $\mathrm{pH}$-sensitive microelectrode (ICHIKAWA et al., 1989). The results showed that ECF acidification occurred with the occlusion of the principal artery supplying the tested regions, and that the $\mathrm{ECF} \mathrm{pH}$ response to a vertebral injection of $\mathrm{CO}_{2}$-saturated saline was diminished during the occlusion. In the present study, it seemed that the phrenic activity during the occlusion of AICA changed in just such a manner. Therefore, we were able to assume that AICA perfused the central chemoreceptors. However, not all data of occlusion studies have supported this hypothesis. Particularly, phrenic activity did not increase during the occlusion of AICA in 19 cats and increased during the occlusion of PICA in 2 cats. In these cats, blood flow of the artery other than AICA or PICA may be mainly related to central chemoreception. 
On the other hand, bilateral occlusions of AICA and PICA induced a decrease or even disappearance of not only spontaneous phrenic activity but also the phrenic response to a vertebral injection as well as to electric stimulation of the sinus nerve. This shows that multiple occlusions of principal arteries produce severe ischemia in the lateral medulla, a result which may support the idea of LIPSCOMB and BOYARSKY (1972), who demonstrated that bilateral lesioning of the ventrolateral surface of the medulla designated as a chemosensitive area resulted in apnea, and concluded that the apnea resulted in ischemia of the lateral portion of the medulla and in the respiratory center. Thus, occlusion of principal arteries passing through the vicinity of these chemosensitive areas, that is, occlusion of both AICA and PICA, would impair both the functions of the central chemoreceptors and respiratory center.

Effect of injection into AICA on respiration. In the present study, the main finding was that phrenic activity was dependent on the $P_{\mathrm{CO}_{2}}$ of injected blood into AICA, indicating that the response was mediated by central chemoreceptors of respiration, and supporting the above hypothesis that the central chemoreceptors are located in the area perfused by AICA. However, the phrenic response curve to injected blood $P_{\mathrm{CO}_{2}}$ into AICA shifted toward higher $P_{\mathrm{CO}_{2}}$ compared to that of alveolar $P_{\mathrm{CO}_{2}}$. This means that the phrenic activity was depressed by the injection of blood, although it had the same $P_{\mathrm{CO}_{2}}$ level as that of systemic arterial blood. A similar result was obtained in the relationship between phrenic activity and rostral $\mathrm{pH}$; phrenic activity was depressed by the injection of blood, but the injection with the same $P_{\mathrm{CO}_{2}}$ level did not induce changes in the ventral surface $\mathrm{pH}$. This indicates that injection into AICA might cause inhibitions of phrenic activity through neural structures other than respiratory chemoreceptors. It has been shown that low temperature and hypoxia depress the respiration (SCHLÄFKE et al., 1969; CHERNIACK et al., 1970/1971, 1979). Since the blood used for injection was maintained at $38^{\circ} \mathrm{C}$ and was equilibrated with a normoxic gas mixture, these factors would be irrelevant to the $P_{\mathrm{CO}_{2}}$ response. The other factors, e.g. injection pressure, injection rate, or disturbance of blood flow by the injection, could well be attributable to respiratory depression. Thus, the phrenic response to the injection into AICA can be assumed to be a combination of the inhibition through as yet unknown mechanisms and the $P_{\mathrm{CO}_{2}}$-dependent excitation through the respiratory chemoreceptors.

Location of central chemoreceptors. Because the injected blood into AICA perfused the rostral medulla, it seems likely that the central chemoreceptors are located in the rostral medulla. Furthermore, the marked decrease $(80 \%)$ of phrenic-alveolar $P_{\mathrm{CO}_{2}}$ response during the injection suggests that the respiratory response to $\mathrm{CO}_{2}$ originated partly from this area. The rest $(20 \%)$ of the response indicates that other chemoreceptors exist in other areas and/or stimulating factor(s) other than the injected blood $P_{\mathrm{CO}_{2}}$ exist. From this, it can be assumed that there are at least three possibilities regarding the location of central chemosensitive structures. First, several such strectures may be located separately in the medulla. Secondly, whole chemosensitive structures may be located in the boundary area 
perfused by not only AICA but also other arteries. Lastly, whole chemosensitive structures may be situated in the rostral medulla, but its activity may depend not only on blood $\mathrm{P}_{\mathrm{CO}_{2}}$ but also on the acid-base condition of the cerebrospinal fluid (CSF).

The first possibility was proposed by MITCHELl et al. (1963) and LoESCHCKE et al. (1970). They demonstrated that there were two separate chemosensitive areas in the ventral surface of the medulla, the "rostral (M)" and "caudal (L)" areas. Topographically the perfused area by injections overlapped with the "rostral" chemosensitive area. Furthermore, phrenic activity during injection seemed to be correlated with $\mathrm{pH}$ changes in this area. Thus, the chemosensitive structures in the present study may correspond to the "rostral" area and the phrenic-alveolar $P_{\mathrm{CO}_{2}}$ response during the injection may express the chemosensitivity of the "caudal" area.

On the other hand, CRAGG et al. (1977) proposed that the chemosensors which drive ventilation need not occur superficially but could occur at any depth in the medulla. Our previous studies have also suggested the possibility that $\mathrm{pH}$-dependent central chemoreceptors could be scattered in deeper areas as well as in superficial layers (ARITA et al., 1989; ICHIKAWA et al., 1989). Becuase the injected blood into AICA perfused not only the ventral surface but also deep structures of the rostral medulla (Fig. 10), this hypothesis of scattered receptors could not be ruled out in the present study.

The second possibility arose from the complexity of the cerebral vascular system: Since the cerebral arterial system has extensive anastomoses, it is possible that the chemosensors are concentrated in the perfused area. This concentrated area may be the boundary region perfused not only by AICA but also by other arteries. The present results of confusing data of the occlusion study would support this possibility. Thus, the phrenic-alveolar $P_{\mathrm{CO}_{2}}$ response during the injection may be due to the dilution of the injected blood by blood from arteries other than AICA.

The third possibility was proposed by Mitchell et al. (1963) and by PAPPENHEIMER et al. (1965). They showed that $\left[\mathrm{H}^{+}\right]$sensitive receptors were located in an area of some depth from the medullary surface which was influenced by acid-base reactions of both blood and CSF. This hypothesis could apply to the present results; the whole chemoreceptors are located beneath the ventral surface of the rostral medulla, and its activity was dependent not only on the injected blood $P_{\mathrm{CO}_{2}}$ but also on the CSF acid-base condition. Surface $\mathrm{pH}$ in the rostral medulla during the injection changed slightly with a 1-min inhalation of a hypercapnic gas mixture (Fig. 9). This means that the bulk of CSF $\left[\mathrm{H}^{+}\right]$would be affected by alveolar $P_{\mathrm{CO}_{2}}$ via the systemic arterial blood rather than that of the injected blood, and therefore the rostral surface $\mathrm{pH}$ may change by the inflow of CSF. Thus, the phrenic-alveolar $P_{\mathrm{CO}_{2}}$ response during the injection may express the chemosensitivity to $\mathrm{CSF}\left[\mathrm{H}^{+}\right]$.

In any case, the present study shows that a part of the central chemoreception for respiration is located in the perfused area of AICA, that is, in the rostral medulla. There has been other evidence recently that the rostral ventrolateral medulla contains 
central chemosensitive elements (CAKAR and TERzIOGLU, 1983; BUdzINSKA et al., 1985; MCAllen, 1986; Nattie, 1986).

This study was supported by a Grant-in-Aid for Scientific Research (C) from the Ministry of Education, Science and Culture, Japan (61570053).

\section{REFERENCES}

Arita, H., IChikawa, K., Kuwana, S., and Kogo, N. (1989) Possible locations of $\mathrm{pH}$-dependent central chemoreceptors: Intramedullary regions with acidic shift of extracellular fluid $\mathrm{pH}$ during hypercapnia. Brain Res., 485: 285-293.

Bruce, E. N. and Cherniack, N. S. (1987) Central chemoreceptors. J. Appl. Physiol., 62: $389-402$.

Budzinska, K., Euler, C. von, Kao, F. F., Pantaleo, T., and Yamamoto, Y. (1985) Effects of graded focal cold block in rostral areas of the medulla. Acta Physiol. Scand., 124: 329-340.

CAKar, L. and Terzioglu, M. (1983) Localization of $\mathrm{CO}_{2}$ sensitive units in the rostral medullary chemosensitive area of the cat. In: Central Neurone Environment and the Control Systems of Breathing and Circulation, ed. by SCHLÄFKE, M. E., KoEPHEN, H. P., and SeE, W. R., Springer-Verlag, Berlin Heidelberg, and New York, pp. 52-60.

Chapman, R. W., Santiago, T. V., and Edelman, N. H. (1979) Effect of graded reduction of brain blood flow on ventilation in unanesthetized goats. J. Appl. Physiol., 47: 104-111.

CherniacK, N. S., Edelman, N. H., and Lakirri, S. (1970/1971) Hypoxia and hypercapnia as respiratory stimulants and depressants. Respir. Physiol., 11: 113-126.

Cherniack, N. S., Eular, C. von, Homma, I., and KaO, F. F. (1979) Graded changes in central chemoceptor input by local temperature changes on the ventral surface of medulla. J. Physiol. (Lond.), 287: 192-211.

Cragg, P., Patterson, L., and Purves, M. J. (1977) The pH of brain extracellular fluid in the cat. J. Physiol. (Lond.), 272: 137-166.

ELDRIDGe, F. L., Gill-Kumar, P., and Millhorn, D. E. (1981) Input-output relationships of central neural circuits involved in respiration in cats. J. Physiol. (Lond.), 311: 81-95.

ICHIKAWA, K., KuWANA, S., and ARITA, H. (1989) ECF pH dynamics within the ventrolateral medulla: A microelectrode study. J. Appl. Physiol., 67: 193-198.

Kiley, J. P., Eldíridge, F. L., and Millhorn, D. E. (1985) The roles of medullary extracellular and cerebrospinal fluid $\mathrm{pH}$ in control of respiration. Respir. Physiol., 59: $117-130$.

Kuwana, S. and Natsui, T. (1981) Effect of arterial $\left[\mathrm{H}^{+}\right]$on threshold $P_{\mathrm{CO}_{2}}$ of the respiratory system in vagotomized and carotid sinus nerve denervated cats. J. Physiol. (Lond.), 318: 223-237.

KUWANA, S. and NATSUI, T. (1987a) Effect of hypercapnic blood injection into the vertebral artery on the phrenic nerve activity in cats. Jpn. J. Physiol., 37: 155-159.

KUWANA, S. and NATSUI, T. (1987b) Effect of injection of hypercapnic blood injection into the anterior inferior cerebellar arteries on the phrenic nerve activity in cats. J. Physiol. Soc. Jpn. 49: 541 (abstract).

KuWANA, S. and NATSUI, T. (1988) Inspiratory response to occlusion of arteries in the ventral surface of the medulla in anesthetized cats. Tohoku J. Exp. Med. (Suppl.), 156: $1-9$. 
LIPSCOMB, W. T. and BOYARSKY, L. L. (1972) Neurophysiological investigation of medullary chemosensitive areas of respiration. Respir. Physiol., 16: 362-376.

LOESCHCKe, H. H. (1982) Central chemosensitivity and the reaction theory. J. Physiol. (Lond.), 332: 1-24.

Loeschcke, H. H., De LatTre, J., SchläFKe, M. E., and Trouth, C. O. (1970) Effects on respiration and circulation of electrically stimulating the ventral surface of the medulla oblongata. Respir. Physiol., 10: 184-197.

MCALLEN, R. M. (1986) Location of neurones with cardiovascular and respiratory function, at the ventral surface of the cat's medulla. Neuroscience, 18: 43-49.

MillHORN, D. E. and EldRidge, F. L. (1986) Role of ventrolateral medulla in regulation of respiratory and cardiovascular system. J. Appl. Physiol., 61: 1249-1263.

Mrtchell, R. A., Loeschcke, H. H., Massion, W. H., and Severinghaus, J. W. (1963) Respiratory response mediated through superficial chemosensitive areas on the medulla. J. Appl. Physiol., 18: 523-533.

NATTIE, E. E. (1986) Diethyl pyrocarbonate (an imidazole binding substance) inhibits rostral VLM $\mathrm{CO}_{2}$ sensitivity. J. Appl. Physiol., 61: 843-850.

Pappenheimer, J. R., Fencl, V., Heisei, S. R., and Held, D. (1965) Role of cerebral fluids in control of respiration as studied in unanesthetized goats. Am. J. Physiol., 208: 436-450.

SCHLÄFKe, M. E., SEe, W. R., and LOESCHCKE, H. H. (1970) Ventilatory response to alteration of $\mathrm{H}^{+}$ion concentration in small areas of the ventral medullary surface. Respir. Physiol., 10: 198-212.

SchläfKe, M. E., See, W. R., Massion, W. H., and Loeschcke, H. H. (1969) Die Rolle „spezifischer" und unspezifischer Afferenzen für den Antrieb der Atmung, untersucht durch Reizung und Blockade von Afferenzen an der decerebrierten Katze. Pfiügers Arch., 312: 189-205. 